\title{
Improving quality of health care: the role of public health medicine
}

Department of Epidemiology and Public Health, University of

Newcastle upon Tyne, Newcastle upon Tyne NE2 4HH

Richard Thomson, senior lecturer

Raj Bhopal, professor

Correspondence to: Dr Thomson

Accepted for publication

7 January 1993
This is the first of an occasional series of articles in which different health professionals discuss the contribution of their particular specialty to the quality of patient care.

In the recent debate on the role of the specialty of public health medicine $e^{1-4}$ the stimulation and support of quality improvement in patient care services have received insufficient attention. The disciplines which underpin the practice of public health, particularly epidemiology, statistics, medical informatics, and the management sciences, are highly relevant to improving health care quality. Public health doctors, who represent one of the disciplines within this broad range of expertise, have a vital and legitimate role in contributing to provider led improvement of quality.

The role of the specialty in population health status, health needs, and health care needs assessment has been debated. ${ }^{4}{ }^{5}$ In this paper we shall discuss the potential influence of the specialty in assessing and improving the quality of health care provision. To an extent this is a false distinction: a provider may deliver coronary artery bypass grafts of the highest quality, but if this treatment is not accessible to people who would benefit then the quality of care to the community is suboptimal. However, in this article we concentrate primarily on the contribution of public health to the quality of provider care.

\section{Public health's recent history}

"Public health is the science and art of preventing disease, prolonging life and promoting health through organised efforts of society."

\section{Acheson Report}

In 1972 the specialty of community medicine, now public health medicine, was established from three separate groups: the medical officers of health (whose responsibilities included a range of preventive health services at local authority level), senior administrative medical officers, and academics in social medicine and epidemiology, thus merging disease prevention, medical management, and epidemiology. Therefore, before 1972 the role of public health doctors in developing high quality services was explicit: they were closely involved in the direct management of hospital and preventive services. One of the principal aims of creating the specialty was to bring an epidemiological perspective to the NHS to improve its effectiveness and efficiency. ${ }^{6}$
A major review by the Acheson Committee,${ }^{1}$ followed by the NHS review and the enactment of the NHS and Community Care Act, ${ }^{7}$ have clarified the role of public health as focusing on the measurement of the health status of populations, the promotion of health, the prevention of disease, and the analysis and evaluation of health services. The NHS reforms, particularly the purchaser-provider separation, have emphasised the importance of needs assessment in health and health care and of health promotion and disease prevention at the population level as the primary objectives of health authority public health doctors. The white paper The Health of the Nation further commits the government, health services, and others to a new focus for improving the population's health. ${ }^{8}$ That improvement is the primary goal of the specialty.

\section{Improving the quality of health care}

"Quality in health care: a commodity that is damaged if any changes whatsoever are made in the structure or financing of the current system of medical practice."

CAPER, 1988

Many attempts have been made to define quality in health care succinctly, including the ironic definition above. This may ultimately be a futile activity: it is not so much a definition that is needed but a better understanding of the components of health care quality and of the methods to assess and improve that quality, encompassing ways of obtaining valid perspectives, including those of the public and patients. $^{9-12}$

For our purpose it is important to distinguish between quality of health (encompassing health status assessment) and quality of health care (encompassing the structures, processes, and outcomes of health care). The application of health, and health care needs assessment bridges these two areas. The ultimate delivery of health care quality rests at the individual patient-service interface, but assessment and improvement of quality depends as much on analysis of the delivery and outcomes of health care for groups of patients (medical care epidemiology) as on analysis of the care of individuals. ${ }^{13}$

Quality of health care can be assessed in several ways - for instance, in terms of the structure, process, and outcome of care; the technical interpersonal, and amenity elements; and the client, professional, and management perspective. However, the subdivision is less important than the approaches used to 
evaluate and enhance quality. In health care these range from peer review and audit, through health services evaluation and research, to the application of quality accreditation systems (such as the British Standard BS5750 ${ }^{14}$ and organisational audit ${ }^{15}$ ), and ultimately to total quality management within entire organisations. ${ }^{16}$ Their effectiveness in producing demonstrable improvement in patient care requires data collection and analysis, management of change, and re-evaluation (the quality assurance cycle). Thus effective improvement will require the application of a wide range of skills and methods which are as yet unfamiliar to many health care providers. However, public health training provides many of these skills and an understanding of these methods.

\section{Public health and quality of care}

"[Public health] training in epidemiology and statistics provides a valuable resource for clinical colleagues undertaking medical audit."

The Quality of Medical Care ${ }^{17}$

Public health doctors combine training in clinical medicine with a range of other subjects, including epidemiology, research and evaluation methods, statistics, health service information, management and organisational theory, social sciences, and health service policy. Aligned with these skills is a philosophy and perspective concerned with analysing the determinants of health and disease within populations and applying that knowledge to improve the public's health. ${ }^{18}$ Thus public health doctors study the incidence and prevalence of disease (disease epidemiology); assess health and health care needs; and evaluate the quality and effectiveness of health services for populations and groups of patients (medical care epidemiology). Furthermore, public health doctors work closely with others with specialist knowledge, most commonly social scientists and statisticians.

However, appropriate skills and training are not sufficient to justify a major role for public health medicine in provider led quality of care. That requires demonstration of valuable past contributions and, more importantly, evidence that such involvement would help to improve the health of the population. Public health's past contributions have included analysis and understanding of variations in medical practice and in mortality after common surgical procedure ${ }^{19}{ }^{20}$; studies of variation in the use of investigative tests and the effects of guidelines in changing practice ${ }^{2122}$; developing the infrastructure to support surgical audit ${ }^{23}{ }^{24}$; assessing readmission rates ${ }^{25}{ }^{26}$; waiting list analysis ${ }^{27-29}$; evaluating the use of occurrence screening as a method of audit ${ }^{30}$; evaluating audit methods ${ }^{3132}$; and assessing medical audit publications. ${ }^{33}$ Much of this work has entailed close collaboration between public health doctors and other colleagues. Thus, public health doctors have a firm base, not only scientifically and technically but also in conceptualising and championing the issues. $^{34-37}$

Public health doctors have also been active in improving the quality of their own work. The quality of the work of the specialty needs to be audited and mechanisms introduced to ensure continual improvement. ${ }^{38}$ To contribute effectively to improving the quality of patient care it is important that public health doctors develop experience of the methods for achieving improvement and show commitment to evaluating their own work. Though cyclical audit ${ }^{39}$ is one model for improvement of quality in public health practice, the features of that practice, particularly those of multidisciplinary work and senior management functions within purchasing authorities, lead us to believe that over time the concepts and techniques of total quality management or, to use Don Berwick's preferred phrase, continuous quality improvement, will be more fruitful. ${ }^{34}$ 40-42 Though published evidence of audit in public health medicine is limited, ${ }^{43}$ considerable activity aimed at improving quality of public health practice through audit and quality improvement programmes is under way. ${ }^{44-48}$

Do such contributions improve the health of the population? Many factors influence health, ranging from individual lifestyle, poverty, housing, employment, and environmental pollution through to health services, including those for health promotion, disease prevention, care, cure, and rehabilitation.

Major changes in the population's health have followed changes in economic prosperity, diet, sanitation, and housing. ${ }^{49}$ Current challenges to public health also include economic, environmental, and lifestyle factors such as poverty, housing, pollution, unemployment, smoking, sexual health, and diet. However, recognition that the environment in its broadest sense, rather than health services, is the prime determinant of health does not diminish the importance of health service provision in contributing to improved health of individuals and the population. Public health doctors have an interest in ensuring that health services offer treatment and interventions of proven benefit and that these are applied to maximum benefit to the health of the population. Effective provider led quality improvement programmes will be a necessary part of achieving this potential. Public health doctors thus have a role in applying their skills to support quality improvement as part of the goal of improving the health of the population.

Public health doctors thus have both a proven record and a justification for involvement in improving quality of health care.

\section{Potential contributions of public health doctors}

Public health doctors can contribute to improving provider based quality of care in several ways, as follows.

- Indirect contributions as a purchaser of services through contractual specification 
- Direct contribution through collaborative work with providers

- Enabling the views of the public and patients to be articulated and responded to (both purchaser and provider elements)

- Research into, and evaluation of, quality improvement methods

- Education and training.

\section{INDIRECT CONTRIBUTION: THE PURCHASING} ROLE

Public health doctors help to ensure that services purchased meet the identified health needs and health care needs of the local population. The specialty therefore has a key role in assessing the potential of services purchased for, and developed on behalf of, local populations and in influencing purchasing decisions so that resources are targeted towards areas of demonstrated value and away from areas of unproven efficiency. ${ }^{56}$ However, purchasing the "right" portfolio of services does not guarantee their quality. Purchasers must also consider the quality of the services, for the actual outcomes may differ from the potential outcomes (effectiveness rather than efficacy).

Clearly, the purchaser/provider split offers an opportunity to define more distinctly the strategic role of health authorities by separating it from the operational management of services and hence contributes to a more explicit approach to the commissioning and delivery of services. However, there is concern that the relationship between purchaser and provider may become unnecessarily adversarial. Health authorities have a duty to review the quality of care provided for their population and to ensure that effective quality improvement programmes are in place. Providers will need to demonstrate this. Some of the present sensitivities at the purchaserprovider interface, including the concerns about the confidentiality of medical audit, may inhibit the development of shared understanding. This in itself could undermine or compromise quality of care. A common understanding of the potential of quality improvement methods, including those of total quality management, ${ }^{40-42}$ and their application is essential between purchaser and provider.

Herein lies an important task for public health doctors, that of bridging the interests of purchasers and providers for the better care of the population. They should contribute to the specification of contracts, including the quality components, and to the interpretation of the results of provider based quality improvement programmes on behalf of the purchaser. They can also help to ensure that the demands made on providers for information on quality through the contracting process are appropriate and realistic. Finally, they can contribute to implementing required changes through the policy making process of purchasing organisations.

DIRECT CONTRIBUTION: PROVIDER BASED AUDIT AND QUALITY IMPROVEMENT

We believe that public health doctors can also contribute directly to the development of medical audit and, increasingly, interprofessional audit and total quality management programmes at the provider level. For example, they could usefully contribute to selection of priority topics for quality improvement; giving advice on appropriate methods, study design, and analysis; enhancing understanding of the availability, quality, and uses of NHS information; disseminating and communicating the findings of studies; and incorporating important findings into policy to maximise their benefit.

Public health doctors working alongside clinical colleagues, for instance, as members of medical audit committees, can enhance the application and understanding of audit, including its potential and its constraints. In particular, their population focus and emphasis on the analysis of aggregated data are necessary counterpoints to the individual patient based, peer review approach. Skills in managing change and experience in multidisciplinary working of public health doctors can support the development of effective interprofessional audit and quality improvement. Contributions in the recent past reveal the potential benefits of further participation of the specialty in audit and quality improvement at provider level. ${ }^{21-24} \quad 30-32$

\section{VIEWS OF PATIENTS AND PUBLIC \\ "The health of the people is the concern of the people themselves."}

LENIN

The health service, previously criticised for its lack of responsiveness to the views, wishes, and expectations of the public and patients, ${ }^{50}$ is changing as a result of wider recognition that quality improvement requires the perspective of service users and that public services should be more accountable. ${ }^{51}$ The new population focus of district health authorities and family health services authorities emphasises their role, with that of others such as community health councils, in articulating the views of the public.

For this we need methods of obtaining the unbiased views of the public and patients and mechanisms for responding to these views by creating change. Public health has a responsibility to focus the attention of providers and purchasers on users' views and to ensure that valid methods are used to collect them. Public health doctors (and colleagues within public health departments ${ }^{52}$ ) are skilled in planning, analysing, and interpreting surveys of representative populations, which are the principal tools for incorporating users' perspectives into both purchasing decisions and quality improvement programmes.

RESEARCH INTO HEALTH CARE QUALITY IMPROVEMENT

\footnotetext{
"The science of evaluation is an area of neglect between biomedical research and clinical practice."
}

PECKHAM $^{53}$ 
We should ask challenging questions of audit and quality improvement. Are audit or quality improvement projects and programmes effective in producing desired change? What are the features that help to define effective approaches to audit and how can these be enhanced to increase the cost effectiveness of programmes? What are the most effective mechanisms for stimulating quality improvement? These are important questions in the public health tradition. Thus public health doctors have another role, in evaluating or auditing quality improvement methods. ${ }^{31} 3254$

We therefore welcome the recent announcement of an NHS research and development strategy, including the appointments of national and regional directors, and the intention to identify priorities for research and to apply and disseminate the findings. ${ }^{53}$ This will inevitably lead to a greater emphasis on research into methods for assessing quality improvement and into outcomes of care, ${ }^{55} 57$ where the specialty has a distinct contribution to make.

\section{EDUCATION AND TRAINING}

"Education must have an end in view, for it is not an end in itself."

SYBII. MARSIIAI.I.

As the disciplines of audit, quality improvement, and health service evaluation develop, the need will increase for clinicians, managers, and others to learn new skills. Academic departments of public health, the usual medical school base for epidemiologists, medical statisticians, and social scientists working in health care, ${ }^{52}$ are well placed to meet these needs in management and professional education programmes. Without such support the availability and application of necessary skills will continue to be limited and the aspirations for systematic quality improvement will fail to be realised, not because of shortcomings of the methods themselves but through scarcity of knowledge and skills.

\section{Conclusions}

There are considerable potential benefits for public health doctors; clinical and managerial colleagues; and, ultimately, for the public's health, in the active involvement of the specialty of public health medicine in health care quality assessment and improvement programmes. The benefits to the specialty lie in the potential to influence services to have a greater impact on the health of the population. The benefits to other professional groups lie in the opportunity to add an epidemiological and social science perspective to enhance the design, analysis, interpretation, and application of work on health care quality. The benefits to purchasers lie in the potential for better informed purchasing of services of known quality, which are acceptable to the public, and which are purchased from providers whose quality improvement programmes have been imbued with both clinical and population perspectives
As the specialty struggles with the immense agenda of the NHS reforms, coming to terms with the increased responsibility for health status and health needs assessment, there is a risk that other valuable contributions within the NHS might be neglected. One such area is the considerable potential to influence the quality of care for patients. Though much of the present reform within health care in the United Kingdom may seem to be based on structural change, two central features will continue long beyond the present reconfiguration: the emphasis on the population's health and the increasing profile of quality improvement. Public health has key roles in both; it should be concerned not only with the health and health care needs of populations but with the quality of care provided to the population. It would be sad to look back in 10 years and conclude that the specialty missed the opportunities for improving quality of care.

We thank Drs Alan Mordue and Martin White for their valuable comments during the writing of this paper.

1 Department of Health. Public health in England. London HMSO, 1988

Department of Health. Health of the population: responstbilities of Health Authorities. (HC(88)64)

Ashton J Acheson: a missed (Hepportunity for the new public health. BMF 1988;296:231-2

Whitty P, Jones I. Public health heresv: a challenge to the purchasing orthodoxy. BMF 1992;304:1039-41

5 Stevens A, Gabbay J. Needs assessment needs assessment. Stevens A, Gabbay J. Needs a
Health Trends 1991;23:20-3.

6 Cochrane AL. Effectiveness and efficiency: random reflection on the health servici, London: Nuffield Provincia Hospitals Trust, 1972

7 NHS and (ommunity (are Act, 1990. London: HMSO, 1990

8 Secretary of State for Health. The health of the nation. London: HMSO, 1992 (Cm 1523.) Royal A. Measurng the quality of my

Ovretreit J. Health service quality. An introduction to qualits
(o) methods for health services. Oxford: Blackwell Scientific Publications, 1992

11 Berwick DM, Blanton Godfrey A, Roessner J. Ciuring health care: new strategies for quality improvement. San Francisco Jossey-Bass, 1991

12 Donabedian A. Exploration in quality assessment and monitoring. Vols 1-3. Ann Arbor, Michigan: Health Administration Press, 1980

13 Caper P. The epidemiologic surveillance of medical carc Am f Public Health 1987;77:669-70.

14 McDonald I. Coming up to standard. Int 7 Health Car Qual Ass 1991;4:17-20.

15 Shaw C, Brooks TE. Health service accreditation in the United Kingdom. Quality Assurance in Health Care 1991 United Kingdom. Quality Assurance in Health Care 1991

16 Deming WE. Out of the crisis. Cambridge, Massachusetts: Massachusetts Institute of Technology, 1986

17 Standing Medical Advisory Committee. The quality of medical care. London: HMSO, 1990.

18 Faculty of Public Health Medicine. Training, examination regulations and syllabus. London: FPHM, 1986.

19 Fowkes FGR, McPake BI. Regional variations in out patient activity in England and Wales. Community $M_{i}$ 1986;8:286-91.

20 Charlton JRH, Hartley RM, Silver R, Holland WW Geographical variation in mortality from conditions amenable to medical intervention in England and Wales. Lancet 1983;i:691-6.

21 Fowkes FGR, Hull R, Jones JH, Scanlon MF, Elder GH, Hobbs DR, et al. Trial of strategy for reducing the use of Hobbs DR, et al. Trial of strategy for redur

22 Fowkes FGR, Evans RC, Williams LA, Gehlback SH, Cooke BRB, Roberts CJ. Implementation of guidelines for the use of skull radiographs in patients with head injuries. Lancet 1984;ii; 795-7.

23 Black N. Beating the offside trap: developing a regiona approach to clinical audit. Fourmal of Management in Medicine 1989;4:38-42.

24 Gruer R, Gordon DS, Gunn AA, Ruckley CV. Audit of surgical audit. Lancet 1986; i:23-6.

25 Goldacre MJ, Henderson J, Graveney M. Readmission rates. $B M \mathcal{F}$ 1991;302:414

26 Milne $\mathrm{R}$, Clarke $\mathrm{A}$. Can readmission rates be used as an outcome indicator? BM7 1990;301:1139-40). 
27 Goldacre MJ, Lee A, Don B. Waiting list statistics. I Relation between admissions from waiting list and length of waiting list. BM7 1987;295:1105-8.

28 Lee A, Don B, Goldacre MJ. Waiting list statistics. II. An estimate of inflation of waiting list length. $B M F 1987$; 295: $1247-8$.

29 Don B, Lee A, Goldacre MJ. Waiting list statistics. III. Comparison of two measures of waiting time. $B M$ 1987;295:1247-8.

30 Bennett J, Walshe $\mathbf{K}$. Occurrence screening as a method of audit. $B M F$ 1990;300:1248-51.

31 Gabbay J, Layton AJ. Evaluation of audit of medical in patient records in a district general hospital. Quality in Health Care 1992;1:43-7.

32 Gabbay J, McNichol M, Spiby J, Davies SC, Layton AJ. What did audit achieve? Lessons from a preliminary evaluation of a year's medical audit. $B M \mathcal{F}$ 1990;301: 526-9.

33 Bhopal RS, Thomson R. A form to help learn and teach about assessing medical audit papers. BMF 1991;303 1520-2.

34 Thomson RG, Donaldson LJ. Medical audit and total quality management. F Public Health Medicine 1990;12 149-51

35 McKee CM, Lauglo M, Lessof L. Medical audit: a review. f $R$ Soc Med 1989;82:474-8.

36 Black N. Quality assurance of medical care. $\mathcal{F}$ Public Health Medicine 1990;12:97-104.

37 Ruta D, Wilson B. A handbook of medical audit for hospital doctors. Aberdeen: Department of Public Health Medicine, Grampian Health Board, 1992.

38 Faculty of Public Health Medicine. Report of a working group on the audit of public health medicine. London: group on the

39 Fowkes FGR. Medical audit cycle: a review of research and methods in clinical practice. Med Educ 1982;16:228-38.

40 Berwick DM. Continuous quality improvement as an ideal in health care. $N$ Engl $\mathcal{F}$ Med 1989;320:53-6.

41 Berwick DM, Enthoven A, Bunker JP. Quality management in the NHS: the doctor's role. I. BMF 1992;304: 235-9.

42 Berwick DM, Enthoven A, Bunker JP. Quality management in the NHS: the doctor's role. II. BMF 1992;304 304-8.
43 Aplin VCC. Medical audit in public health medicine: a guide to the literature. Southborough, Kent: South East Thames Regional Health Authority, 1992.

44 Joyce L, Radford G, Forrest D. The South West Thames Regional Health Authority approach to the method of audit in public health medicine. $\mathcal{f}$ Public Health Medicine audit in public heal

45 Northern Region Public Health Medicine Audit Promotion Group. Proceedings of a study day on audit in public health medicine. Newcastle upon Tyne: Northern Regional Health Authority, 1990.

46 Eskin F, ed. Audit in public health medicine - a guide for district departments of public health medicine. Harrogate: Yorkshire Regional Health Authority, 1990

47 Nuffield Institute for Health Services Studies. Audit guidelines in public health medicine. Leeds: Nuffield Institute for Health Services Studies, 1992.

48 Gair R, Li Chee Lan L, McKee M, Parikh C, Weinberg J. Criteria for audit of annual reports on the public health: do they exist? $f$ Public Health Medicine 1992;14: 169-72.

49 McKeown T, Lowe CR. An introduction to social medicine. Oxford: Blackwell, 1974 .

50 Department of Health and Social Security. NHS management enquiry. Report London: DHSS, 1983.

51 Department of Health. The patient's charter. London: HMSO, 1991.

52 Clarke M, Kurinczuk JJ. Health services research: a case of need or special pleading? BMF 1992;304:1675-6.

53 Peckham $M$. Research and development for the National Health Service. Lancet 1991;338:367-71.

54 Barton A, Bhopal R, Thomson R, Ennis WP, Holland C. Auditing audit: an academic view. A case for research evaluating medical audit. In: Auditing medical audit. Proceedings of the Conference of the Association for Management Education for Clinicians. Birmingham, 1992.

55 Frater A, Costain D. Any better? Outcome measures in medical audit. $B M \mathcal{F} 1992 ; 304: 519-20$.

56 Elwood PM. Shattuck lecture - outcomes management. A technology of patient experience. $N$ Engl $f \mathrm{Med}$ 1988;318:1549-56.

57 Greenfield $S$. The state of outcome research: are we on target? N Engl f Med 1989;320:1142-3. 